\title{
UM CERTO JEITO DE SER VELHO: REPRESENTAÇÕES SOCIAIS DA VELHICE POR FAMILIARES DE IDOSOS ${ }^{1}$
}

\author{
Rosana Cancelo da Cruz², Márcia de Assunção Ferreira ${ }^{3}$
}

\footnotetext{
${ }^{1}$ Recorte da dissertação - Representações sociais da velhice por familiares de idosos hospitalizados: implicações para a enfermagem, apresentada ao Programa de Pós-graduação em Enfermagem da Escola de Enfermagem Anna Nery (EEAN) da Universidade Federal do Rio de Janeiro (UFRJ), 2007.

${ }^{2}$ Mestre em Enfermagem. Enfermeira da Casa de Saúde República Croácia, Rio de Janeiro, Brasil, e-mail: rcancelo@uol.com.br

${ }^{3}$ Doutora em Enfermagem. Professora Titular do Departamento de Enfermagem Fundamental da EEAN/UFRJ. Pesquisadora do CNPq. Rio de Janeiro, Brasil.. E-mail: marciadeaf@ibest.com.br
}

RESUMO: Os objetivos foram conhecer as representações sociais da velhice por familiares de idosos hospitalizados e discutir suas implicações para o cuidado ao idoso pela família no domicílio. O referencial foi a Teoria das Representações Sociais. Os sujeitos foram 22 familiares de clientes hospitalizados em instituição de longa permanência. A técnica de produção de dados foi a entrevista semiestruturada. Aplicou-se a análise de conteúdo temática, através da qual se organizaram categorias sobre o que é a velhice e ser velho, e indicaram características tipificadoras destes objetos. As representações sociais sobre a velhice a relaciona a uma fase de perdas dando-lhe uma conotação negativa, aludindo a modelos de interações pessoais e sociais, assim como a modos de cuidar do idoso. Conhecer tais representações sociais e as ações que dela demandam é fundamental para se lidar com os familiares, com vistas a que estes cuidem dos idosos no domicílio.

DESCRITORES: Idoso. Cuidados de enfermagem. Psicologia social.

\section{A CERTAIN WAY OF BEING OLD: SOCIAL REPRESENTATIONS OF OLD AGE BY ELDERLY FAMILY MEMBERS}

\begin{abstract}
This study aimed to better understand the social representations of old age among relatives of hospitalized elderly and to discuss their implications for home care by the elderly person's family, according to the Theory of Social Representations. The subjects were 22 relatives of hospitalized patients in a long-term institution. The data was collected through semi-structured interviews and submitted to thematic content analysis, from which the categories about what old age is and being old is were organized, indicating typifying characteristics of these objects. The social representations of old age relate it to a stage of loss and give it a negative connotation, alluding to personal and social interaction models, as well as the ways to care for the elderly. A better understanding of such social representation and the actions which are demanded from it is essential in dealing with family members, considering that they care for elderly family members at home.
\end{abstract}

DESCRIPTORS: Elderly. Nursing care. Social psychology.

\section{UNA MANERA DE SER ANCIANO: REPRESENTACIONES SOCIALES DE LA VEJEZ POR FAMILIARES DE ANCIANOS}

RESUMEN: Los objetivos del estudio son: conocer las representaciones sociales de la vejez por familiares de ancianos hospitalizados, y discutir sus implicaciones para la atención del anciano por la familia en el hogar. La referencia para el estudio fue la Teoría de las Representaciones Sociales. Participaron 22 familiares de pacientes hospitalizados en instituciones geriátricas. La técnica de producción de datos fue la entrevista semi-estructurada. Se aplicó el análisis de contenido temático, a través del cual se organizaron categorías sobre lo qué es la vejez y ser anciano, y se indicaron características que tipifican estos objetos. Las representaciones sociales sobre la vejez la relacionan a una etapa de pérdidas dándole una connotación negativa, aludiendo a modelos de interacciones personales y sociales, así como a maneras de cuidar del anciano. Conocer tales representaciones sociales y las acciones que de ella demandan es fundamental para lidiar con los familiares, con el objetivo de que ellos cuiden de los ancianos en el hogar.

DESCRIPTORES: Anciano. Atención de enfermería. Psicología social. 


\section{INTRODUÇÃO}

Envelhecer é um processo natural, que marca uma etapa da vida do homem, e que se dá através de mudanças físicas, psicológicas e sociais. Com o avançar da idade vão ocorrendo alterações estruturais e funcionais, que são encontradas em todos os idosos, próprias do processo de envelhecimento normal. ${ }^{1}$ No entanto, essas alterações variam de um indivíduo para outro. Se, por um lado, é fácil associar-se algumas manifestações que sejam comuns em idosos como cabelos brancos, rugas, redução da capacidade de trabalho e de resistência, por outro lado é impossível afirmar que elas sejam ditadas exclusivamente pelo processo de envelhecimento, já que fatores genéticos e ambientais podem também estar presentes e interferindo nesse processo. Isso justificaria o fato de que as pessoas não envelhecem da mesma maneira.

A preocupação com o declínio fisiológico ocorrido com a velhice data das épocas mais remotas, assim como com o papel que o velho desempenha na sociedade. Em breve retrospectiva histórica, observa-se que Hipócrates (460-377 a.C.) considerava a saúde resultante do equilíbrio entre quatro humores: sangue, fleuma, bile amarela e bile negra, e a doença e a velhice como uma ruptura nesse equilíbrio. Galeno (século II) considerava a velhice como intermediária entre a saúde e a doença, não sendo a velhice propriamente um estado patológico, mas um estado onde todas as funções fisiológicas ficam reduzidas, ou enfraquecidas. Até o século XVIII, a grande preocupação dos médicos era prevenir a velhice, ainda encarando-a como uma doença, elaborando regimes de saúde e de longevidade. A partir deste século, com o predomínio do racionalismo e do mecanicismo nos modos e se pensar a vida e a saúde, o corpo é comparado a uma máquina, a doença à avaria e a velhice representa o desgaste de suas engrenagens. ${ }^{2}$

Existem diferentes formas de envelhecer, individualmente, e, principalmente, diferentes formas de encarar a velhice; no entanto, vemos sempre correlacionado na história a visão da velhice associada ao desgaste, às perdas e às doenças. Essa correlação tem sido questionada, na atualidade, uma vez que diversas experiências de envelhecimento bem sucedido têm sido retratadas como, por exemplo, nos grupos de convivência e universidades da terceira idade. ${ }^{3}$

Esta pesquisa teve por objetivo conhecer as representações sociais da velhice por familiares de idosos hospitalizados em instituição de longa permanência, e discutir suas implicações para o cuidado ao idoso pela família no domicílio.

\section{MÉTODO}

Pesquisa de caráter descritivo, de abordagem qualitativa. O referencial foi o da Teoria das Representações Sociais (TRS), na sua vertente processual. As Representações Sociais (RSs) são formas organizadas de conhecimento do senso comum, que orientam os sujeitos nas suas ações. ${ }^{4}$ À luz desta teoria, considera-se que os sujeitos sociais elaboram explicações sobre os objetos socialmente relevantes, o que os ajudam a se comunicar e a agir frente às questões que se colocam no cotidiano. As representações sociais expressam saberes, práticas e atitudes, servindo para explicar as múltiplas formas com que os sujeitos lidam com os objetos, no caso desta pesquisa, com a velhice e com o velho. A velhice e o velho são objetos socialmente relevantes, passíveis de representações sociais, mormente para os familiares que se vêem diante da situação de lidar com os idosos dependentes de cuidados.

O cenário foi uma Casa de Saúde classificada como instituição de longa permanência, ${ }^{5}$ no município do Rio de Janeiro. Os sujeitos foram familiares de idosos de cuidados prolongados, com probabilidade clínica para alta hospitalar. Consideraram-se familiares as pessoas com vínculo consanguíneo ou não, que anteriormente à internação conviviam com o idoso na mesma residência. Os critérios de inclusão consideraram a maioridade legal, dezoito anos, e visitar o idoso durante sua hospitalização no período demarcado para a coleta de dados.

Para a definição da amostra utilizou-se o critério de recorrência de dados, encerrando-se a fase de coleta na medida em que a pré-análise delineou o quadro empírico da pesquisa para o alcance dos objetivos. No total, participaram vinte e dois sujeitos, sendo vinte do sexo feminino e dois do masculino. A faixa etária variou de vinte e dois a sessenta e sete anos, com predominância da faixa de quarenta e um a cinquenta anos.

A técnica de produção de dados foi a entrevista individual, com roteiro semi-estruturado. As entrevistas foram realizadas na própria instituição, no período de março a maio de 2007. Para o primeiro contato com os familiares aproveitou-se o horário de visitas, quando foram explicados os objetivos da pesquisa e solicitada sua participação. As entrevistas foram realizadas imediatamente ou agendadas para dia e horário de acordo com a disponibilidade do entrevistado. 
Aos conteúdos foram aplicadas técnicas de análise temática que originaram mapas com o agrupamento do material verbal coletado, de acordo com suas semelhanças e características comuns, formando uma grande linha organizadora do discurso sobre a concepção da velhice. Esta grande linha se desdobrou em duas categorias temáticas que indicaram o que é a velhice/ser velho e que características tipificam o ser velho.

O projeto foi aprovado pelo Comitê de Ética em Pesquisa da Escola de Enfermagem Anna Nery e Hospital Escola São Francisco de Assis, de acordo com o protocolo de $n^{0} 003 / 07$. Todos os sujeitos assinaram o Termo de Consentimento Livre e Esclarecido. $\mathrm{O}$ anonimato foi garantido por códigos: codinome, idade, vínculo com o idoso.

\section{RESULTADOS E DISCUSSÃO}

Os resultados se assentam nas características que marcam os sujeitos e o objeto da RS, familiares de idosos internados que necessitam de cuidados prolongados, ou seja, idosos nos quais está presente, com frequência, a associação de várias entidades patológicas, com alto grau de dependência. Portanto, os familiares têm a experiência de vida com esse tipo de idoso - doente e dependente. Como a RS se configuram a partir da experiência vivida de cada indivíduo, a RS da velhice nesse grupo é marcada por essa realidade, ou seja, a vivência com idosos doentes, debilitados e em geral, dependentes, o que lhes trazem grandes desafios para o cuidado de tais idosos. ${ }^{6}$

Talvez, ou provavelmente, a mesma pesquisa realizada com outro grupo, em outra realidade social, com uma experiência de lidar com uma velhice diferente, possa gerar outras respostas, ainda que se tenha claro que as RS se constroem à luz dos grupos sociais, e mesmo que a pessoa não vivencie na família uma determinada situação, participa de discussões, conversas e comenta os assuntos veiculados pela mídia sobre os mais variados objetos, no caso em questão, a velhice. A partir daí, vai agregando os elementos da experiência vivida na vida privada e no âmbito social, reunindo informações, opiniões e os sentidos sociais que as outras pessoas com as quais convive comunicam. Tudo isso, em conjunto, constrói as RSs.

Os resultados da análise de conteúdo geraram categorias que se formaram a partir de unidades de registros que se organizaram em tópicos assemelhados que aludiram ao que os sujeitos entendem sobre o que é a velhice e o que é ser velho, e indicaram características tipificadoras destes objetos.

\section{O que é a velhice/ser velho é}

Esta primeira categoria remete à idéia de envelhecimento como um momento de perdas.

A gente vai perdendo as forças, a energia. A gente vai perdendo tudo. Você passa dos 60 , você vai sentindo um cansaço, ainda mais se você começou a trabalhar muito cedo, vai batendo o cansaço (Ana, 67, acompanhante).

Acho que é muito triste, porque a pessoa perde as forças e fica fraca, cansada, desanimada. Ah, é da velhice mesmo. Vai perdendo as forças, sabe? (Tânia, 38, sobrinha).

Essas perdas podem ser caracterizadas de diversas formas: a perda dos amigos, da força produtiva, da saúde e da beleza. Na perda dos amigos, os sujeitos levantam a questão da finitude da vida e da proximidade da morte. A velhice acarreta um sentimento de falta de expectativa de vida, relacionada à inexorabilidade da morte, à impossibilidade de se lutar contra ela.

Fica parado, vendo a vida passar, só esperando a morte chegar. Vocêjá pensou que tristeza, você envelhecendo e vendo seus parentes, seus irmão, seus vizinhos da sua idade tudo morrendo? Só deve ficar pensando: "-o próximo sou eu" (Mara, 47, filha).

A morte de pessoas próximas significa uma ruptura com o passado e isto faz com que o velho seja considerado como "alguém que tem muitos mortos por trás de si". 2:452 A morte de um familiar ou de um amigo não priva o idoso apenas de sua presença, mas da parte da vida que estava ligada a essas pessoas que se foram. A frequência com que os idosos vão passando por essa experiência causa-lhes um contínuo sentimento de perda, de descontinuidade, levando-o a cada vez mais pensar na proximidade da morte, fato bem marcado nas RSs da velhice dos sujeitos desta pesquisa. Ressalta-se que estas RSs são compartilhadas pelos sujeitos idosos, com mais de 60 anos, e pelos que não o são.

Ressalta-se que o medo da morte, o temor pelo fim da vida, ligados à imagem da velhice, faz com que as pessoas se afastem do idoso, buscando assim afastar também a velhice e a morte, como se isso fosse possível. Esse afastamento pode gerar o abandono e reclusão do velho, seja em sua própria residência, seja em instituições hospitalares ou asilares. Isto mostra a dimensão prática ${ }^{4}$ desta RS da velhice, confirmando o potencial de aplicação da TRS a este estudo e a funcionalidade da Teoria. ${ }^{7}$

A perda da força de trabalho também marca as RSs da velhice, e remete à questão da visão do 
corpo como instrumento de trabalho, característica das sociedades ocidentais capitalistas contemporâneas, e das dificuldades e consequências que essa perda acarreta no velho/velhice.

Vai ficando feia, acabada, com um cansaço mortal, sabe? Tudo fica difícil, uma coisa que antes a gente fazia com a maior facilidade, agora se torna difícil, custoso (Fani, 62, irmã).

Antes ela era forte, trabalhava, sempre trabalhou, (Tânia, 38, sobrinha).

Na sociedade ocidental e capitalista, "qualquer valoração fundamenta-se na idéia básica da produtividade, inerente ao próprio capitalismo" ${ }^{\text {8:423 }}$ Dessa forma, o indivíduo, com a diminuição da força de trabalho característica da velhice, torna-se um ser incapaz de produzir, perdendo seu papel na sociedade onde predominam os valores relacionados à capacidade para o trabalho e independência, tendo sua condição desvalorizada. Passa então a depender do auxílio do estado, objetivada através da aposentadoria, da assistência gratuita à saúde, de benefícios como passe-idoso.

A oposição jovem-forte $x$ velho-fraco é claramente expressa e compartilhada pelos sujeitos,

Quando ele era novo era forte, um homão [...] bebia e tudo, mas era forte. Trabalhava, dava um duro danado, cuidava da gente. Mas depois que envelheceu, foi ficando cada dia mais fraco, parou de trabalhar. Depois que envelhece, parece que a vida despenca, sabe? Tudo fica mais difícil, porque a gente está fraco (Gina, 51, esposa).

A inconformidade com a perda da força está intimamente ligada à juventude. Ser jovem é ser forte. Ser velho é ser fraco, sem forças para lutar. Não só o velho se sente assim, mas também a sociedade lhe reforça a idéia, quase que diariamente, principalmente através dos meios de comunicação, de que bonito é o jovem, que é forte.

Diretamente relacionada a essa questão de forte $\mathrm{x}$ fraco, identifica-se a associação da velhice com a doença, que se mostra definitiva para os sujeitos desta pesquisa.

A saúde é muito importante. E a maioria dos velhos não tem saúde (Ana, 67, acompanhante).

Ah, mas é difícil, muito difícil ver um velho sem doença nenhuma. Alguma coisa sempre tem (Mila, 47, filha).

Só de estar velho já é uma doença, né não? (Vera, 59, irmã).

De um modo geral, os idosos possuem várias doenças coexistentes. Estudos populacionais demonstram que a maioria dos idosos (85\%) apresen- ta pelo menos uma doença crônica, e que cerca de $10 \%$ possui, no mínimo, cinco dessas patologias. ${ }^{9}$ Esse quadro comum na velhice vem corroborar a imagem de associação da velhice com doença, ajudando a formar e a reforçar esta RS.

Com o passar dos anos ocorre um aumento exponencial da prevalência de entidades patológicas, ocasionando também um aumento na mortalidade. ${ }^{1}$ No entanto, é também fato que nem sempre é possível estabelecer os limites entre senescência, que seria definida como as modificações peculiares do envelhecimento e a senilidade, definida como modificações decorrentes de processos mórbidos mais comuns em idosos. Desta forma, se para o cientista essa diferenciação é difícil, podemos imaginar que também o seja para o familiar, que associa o envelhecimento com doença, gerando o estereótipo de que velho é sempre doente. Esse quadro de coexistência de múltiplas doenças, aliado ao fato de ser difícil identificar quais manifestações se referem à doença e quais são alterações esperadas e normais, representa um dos motivos da dificuldade do diagnóstico e tratamento dos idosos, enfrentada pela maioria dos profissionais.

A partir dessas duas últimas análises sobre a associação feita entre jovem-forte $x$ velho-fraco $e$ velhice $x$ doença, podemos dizer que a compreensão da velhice se dá na linha do tempo na oposição com a juventude e na oposição com a saúde, pois o velho está diretamente relacionado à doença. As RSs do velho se constroem em oposição, em comparação à representação da juventude, que está associada à força. A velhice é pensada em comparação e oposição à juventude. Isto leva a um desmerecimento e desqualificação das características próprias da velhice em virtude do enaltecimento das características da jovialidade. Nesse sentido, a velhice acaba ficando em desvantagem porque não é pensada em si mesma, mas sempre em relação a algo ou alguém, que é sempre o mesmo que foi e não é mais. Daí a imagem da perda e da doença.

Ao envelhecer e se tornar fraco, o velho se torna susceptível a doença. Por isso a correlação da velhice com a doença - se não existe velho forte, consequentemente ele será doente porque está fraco, sem forças para lutar. Só luta quem é forte, e essa é uma qualidade que o velho não possui. A velhice o enfraquece e abre as portas para a doença. Dessa forma, a doença está naturalizada na velhice. Não há estranhamento. É natural e esperado o velho estar doente. E este é um aspecto importante das RSs deste grupo. 
As representações dominantes sobre o processo saúde-doença são concebidas no discurso biomédico, hegemônico na produção do conhecimento e no campo da saúde. Assim, a doença é considerada um defeito que precisa ser corrigido. O capitalismo reforça a representação do corpo como máquina e como força de trabalho, feito para produzir, e que quando deixa de suprir sua função precípua, necessária para a manutenção do sistema, perde seu valor, ${ }^{10}$ e este pensamento do universo da ciência se impregna no senso comum alimentando a construção das RSs da velhice.

Ora, se o velho não produz, perde a capacidade de contribuir para a grande engrenagem, não tendo valor em uma sociedade capitalista. $\mathrm{O}$ ideário capitalista leva a crer que a velhice seja um estado que dá prejuízo à produção, uma vez que nesta fase, por conta do declínio biológico, o corpo perde gradativamente sua capacidade de trabalho.

Dessa forma, vemos o discurso do senso comum se apropriando do discurso científico para elaborar e re-criar sua representação da velhice - a velhice está ligada à fraqueza, que leva à doença e ao desmerecimento social.

É natural. É como uma máquina. A máquina, não passa o tempo, ela não dá defeito? Então, nosso corpo também é uma máquina, vai passando o tempo, vai dando defeito. E defeito na gente é doença (Paula, 32 , sobrinha).

Apesar de o jovem também ficar doente, é forte e, por isso, tem forças para lutar contra a doença. Já o velho, sem força, não tem como lutar contra ela.

Quando era novo era forte, a doença não pegava ele não (Gina, 51, esposa).

Você encontra um jovem cansado e sofrido? Até tem, mas é da maneira deles, eles é que se fazem assim. $O$ velho já não tem como reagir. O jovem ainda tem, ainda tá começando. Mas o velho não agüenta mais, o jovem tá indo, o velho já tá voltando (Ana, 67, acompanhante).

Acho que quando a pessoa fica velha, fica mais fraca, aí a doença pega de jeito. Por isso que a maioria dos velhinhos é assim, doentinho. É porque fica mais fraco, e não consegue lutar com a doença (Rebeca, 34, acompanhante).

A construção da imagem sobre a velhice não tem uma relação de unicidade com o processo físico de envelhecimento, mas principalmente com o contexto econômico e social. Por isso, afirma-se que a velhice seja uma construção social, não sendo apenas uma manifestação da subjetividade, isto é, de sentir-se velho, mas uma realidade biológica que se relaciona de forma profunda com o contexto social e histórico. ${ }^{11}$ Nessa perspectiva, a associação de velhice com doença resulta de um processo de produção social que, em última análise, guarda estreita relação com a perda da juventude e de sua força característica.

Nas RSs, as imagens ganham força, ${ }^{4}$ e a imagem que se cria do velho é feia, pois a perda da beleza, caracterizada como o surgimento de sinais físicos próprios da velhice, é feita sempre em oposição à do jovem-belo.

Vai caindo cabelo, a pele enruga, a coluna entorta. Veja só que coisa mais triste. Às vezes a pessoa foi uma mulher linda quando era jovem, aí vai ficando velha e vê sua beleza indo embora (Mila, 47, filha).

Olha, velho é aquela pessoa enrugada, de pele feia, de cabelo branco (Célia, 40, filha).

Pra eles deve ser muito difícil vê,r assim, a beleza indo embora (Mara, 47, filha).

Devido à exacerbação da atenção dada na sociedade contemporânea ao corpo, especialmente ao corpo sadio, vigoroso e ágil, a velhice acarreta um sentimento de incômodo, em virtude da sua inexorabilidade, "independentemente de todos os saberes que investigam o corpo humano na tentativa de adiar sua chegada e a da própria morte". ${ }^{12: 7}$

Os idosos se deparam com várias perdas significativas com o passar dos anos: a viuvez, o surgimento das doenças crônico-degenerativas, a morte de amigos e parentes, a ausência de papéis sociais valorizados, o isolamento crescente, as dificuldades financeiras decorrentes da aposentadoria, que tendem a afetar a autoestima do idoso, resultando em crise. ${ }^{13} \mathrm{O}$ enfrentamento dessa crise dar-se-á de uma forma positiva ou negativa, de acordo com o posicionamento que o indivíduo assumiu durante toda sua vida, sua inclusão em seu meio social e as experiências vividas. Poderá enfrentar essas perdas e superá-las, ou sentir-se incapacitado para tal. As modificações orgânicas indicativas da passagem do tempo, como rugas, cabelos brancos, pós-menopausa, postura encurvada, reflexos mais lentos também atuam transformando a auto-imagem do idoso, podendo gerar transtornos emocionais, sem falar nas doenças, principalmente as crônico-degenerativas, que mesmo que se considere que envelhecer não seja sinônimo de adoecer, temos que concordar que sejam mais frequentes nos idosos. 
A representação social da velhice observada nesse grupo em especial, formado por idosos e também por jovens de idades variadas, indica que a velhice é vista como peso social, ligada a improdutividade e à doença. No caso dos idosos participantes deste estudo, quando se deparam com sua própria velhice, no momento em que vivenciam essa realidade, trazem à tona ideias preconceituosas e preconcebidas, interiorizando a velhice com imagens negativas, fortemente construídas e materializadas, associadas ao ser velho.

\section{Velho: um certo jeito de ser/estar}

Atendendo ao questionamento sobre o que é ser/estar velho, a análise do conteúdo das unidades de registros extraídas dos depoimentos demonstrou que há um certo jeito de ser que caracteriza a condição do velho. Esse jeito de ser tem a ver com alterações principalmente emocionais ou psíquicas, gerando um estereótipo de velho ligado a condições negativas como rabugento, chato, teimoso, implicante e cheio de manias.

Porque a gente fica assim, como é que diziam antes, ranzinza. A gente quer as coisas no lugar, entende? Ai tem um jovem dentro de casa, desarruma tudo, a gente quer tudo arrumadinho, você quer chegar e encontrar tudo onde deixou, muito sistemático. Se faltar luz eu sei justamente onde tem uma caixa de vela, vou de olho fechado, tudo no escuro e eu vou de olho fechado pegar. [...] A gente começa a reclamar dentro de casa. Aí vem e fala: -Ah, você é chata (Ana, 67, acompanhante).

Ah, minha filha, você não sabe que velho é cheio de manias?(Marta, 65, irmã).

Os idosos refugiam-se nos hábitos e nas rotinas porque sair da rotina para eles é amedrontador e cansativo. A mínima desordem causa irritação e insegurança no velho, que já não tem aquela capacidade de adaptação e de reagir ao novo, como anteriormente possuía.

Pode-se refutar dessa caracterização do velho, alegando que elas não são peculiares dessa faixa etária, já que se observa no cotidiano que também há jovens rabugentos, ranzinzas, chatos, tristes, cansados e doentes. A personalidade das pessoas não se constrói na velhice, mas se mantém ou se acentuam as características que já possuíam antes. ${ }^{14}$ No entanto, nas RSs dos sujeitos desta pesquisa, se observam referências contrárias a essa afirmação, com a alegação de que essas características tenham surgido após o envelhecimento, como se o velho ficasse de um determinado jeito como se antes não o fosse.
Características peculiares como teimosia e rabugice aparecem em contraposição à juventude compondo um 'certo jeito de ser do idoso', naturalizado na velhice. ${ }^{15}$

Nem que a gente não queira, a gente fica (Ana, 67, acompanhante).

Quando é nova, a gente diz que não vai ser assim, mas que depois fica, sem nem perceber (Fani, 62, irmã).

A análise das unidades de registros extraídas dos depoimentos mostra a questão de que esse seja um processo irremediável, do qual não se perceba quando começa nem se possa fugir. Em consequência, tais representações implicam no cuidado ao idoso, principalmente no domicílio, pois os familiares participantes desta pesquisa demonstram sentimentos contraditórios ao afirmarem que o melhor lugar para o idoso é o domicílio, mas assumem que diversas situações podem inviabilizar esse cuidado, como estar o idoso acamado ou apresentar um quadro de desorientação. Sinalizam também as inúmeras dificuldades de se realizar o cuidado no domicílio, como sobrecarga de trabalho, desarranjo da estrutura da casa e da família entre outros.

Levando-se em consideração as características apresentadas como inerentes ao 'certo jeito de ser idoso', os entrevistados consideram que prestar cuidados ao idoso no domicílio exige que alguns atributos ou qualidades estejam presentes, como paciência, carinho e amor. $\mathrm{O}$ 'certo jeito de ser idoso' exige que haja 'um certo jeito de ser do cuidador'. De certa forma, agir com paciência, carinho e amor representa uma estratégia utilizada para suplantar as dificuldades que surgem durante o cuidar, que são geradas principalmente pelo 'certo jeito de ser idoso'. Nesse sentido, se não houver na família alguém com características apropriadas para dar conta do 'jeito de ser do idoso', torna-se inviável cuidar do idoso no domicílio, reforçando a necessidade de sua institucionalização.

Conhecer os elementos que à luz das RSs da velhice por familiares de idosos tipificam o cuidador é de grande relevância para que se possam entender as escolhas das famílias acerca de qual familiar será responsabilizado diretamente pelo cuidado do idoso, haja vista que, no Brasil, as famílias são o, primeiro recurso para atender e acolher os idosos que necessitam de cuidados prolongados, ${ }^{16}$ a exemplo dos sujeitos e idosos foco da pesquisa em tela.

À luz da TRSs, essa visão consensual que o grupo carrega sobre a velhice é um guia para as 
ações e trocas cotidianas, evidenciando uma das funcionalidades das representações sociais. ${ }^{7}$

Desta feita, considerando que a enfermagem tem importante papel no campo da saúde e educação, mormente se destacando na área de gerontologia, ${ }^{17}$ há que se levar em conta os elementos que constituem as RSs da velhice na abordagem do cuidado no que tange o processo de envelhecimento.

\section{CONSIDERAÇÕES FINAIS}

Os resultados obtidos revelam que estes, sem exceção, trazem nas suas representações sobre a velhice uma conotação negativa, reconhecendo no velho algumas características que consideram serem peculiares a eles. Assim, para esses familiares, a velhice, não é determinada apenas pelo critério cronológico, pelo passar dos anos, mas também sofre influência de fatores biológicos e psicológicos. Estes últimos sendo muito mais valorizados por esses sujeitos, à medida que a velhice está condicionada a 'um certo jeito de ser', reconhecido por características psicológicas, muito mais do que por características físicas, relacionadas ao modo de pensar e de agir, ao comportamento frente às situações vividas e ao estado de espírito do velho.

Resulta então desta pesquisa, que as representações sobre a velhice, para o grupo estudado, têm relação muito mais com características psicológicas atribuídas ao velho, a traços da personalidade imputados a ele, do que propriamente com alterações físicas. Este resultado é interessante para ser discutido no âmbito da formação técnicocientífica dos profissionais que cuidam de idosos, pois, em geral, a abordagem dos livros textos usualmente utilizados nos cursos enfatizam de forma importante as alterações físicas advindas do declínio biológico característico na pessoa idosa, e, ainda, vê-se também ênfase nos aspectos da socialização. No entanto, as características mais marcantes nas representações sociais dos sujeitos foram, justamente, as de cunho psicológico, talvez porque estas tenham uma implicação mais direta com os laços de relação e convivência necessários de serem construídos entre os cuidadores e os idosos, no cuidado no domicílio.

Esta pesquisa mostrou que a representação que os sujeitos têm sobre a velhice influencia nas perspectivas que têm sobre sua própria velhice, gerando sentimentos de medo e mecanismo de negação., além da expectativa de que venham a apresentar também as características que con- sideram serem próprias a ela, como teimosia e rebugice, naturalizadas na velhice.

Conviver com o idoso aponta para uma elaboração pessoal do próprio processo de envelhecimento, criando e re-criando representações sobre a velhice e o ser velho. Se essas representações estão condicionadas a uma concepção da velhice enquanto uma fase da vida ligada a perdas, é esperado que gerem no indivíduo grande expectativa e rejeição, já que configura o que ele espera da própria velhice.

Com esta pesquisa, evidenciou-se que a experiência de conviver com idosos doentes e dependentes, que é uma marca dos familiares sujeitos desta pesquisa, traz indícios de que também podem ser sujeitos de uma velhice sofrida e difícil, já que a velhice é inevitável, não se podendo fugir dela. O aspecto positivo da velhice é uma possibilidade distante da experiência dos sujeitos desta pesquisa, justamente pelas condições de produção de suas representações, que acabam por levá-los a construção de um conhecimento partilhado por histórias comuns de envelhecimento enfermo, dependente, que os orientam a atrelar a velhice a uma fase que gera muitas demandas de cuidados de outrem.

Assim, as RSs do velho/velhice geram atitudes e práticas que podem influir no cuidado do idoso, principalmente quando se está em domicílio, devendo esta questão ser bem refletida no campo da gerontologia.

Apesar de na atualidade haver uma tendência de se formar uma nova visão da velhice, de um envelhecimento mais saudável, as representações encontradas no grupo em questão reafirmam a representação de uma velhice atrelada a perdas, ao abandono e a morte. Pode-se deduzir que pelo fato de os familiares de idosos dependentes terem maior contato com a vivência das limitações ocasionadas pela velhice, faz com que ela seja concebida como um processo de contínuas perdas, em que os indivíduos podem ficar relegados ao abandono e ausência de papéis sociais. Isso de certa forma acaba por contribuir cada vez mais para a perpetuação de mitos, estereótipos, preconceitos e discriminação em relação à velhice, que se manifestam também na postura ao cuidar do idoso. Portanto, torna-se evidente que concepções sobre dependência e cuidado na velhice assumem um papel relevante, na medida em que esses aspectos podem determinar o modelo das interações pessoais e sociais, assim como o modo de cuidar. Sendo assim, conhecer essas concepções e ações que dela demandam é fundamental para 
se lidar com os familiares que convivem e cuidam do idoso no domicílio.

A existência de representações sociais com conteúdos mais positivos e outras com conteúdos mais negativos sobre a velhice mostram a importância de se realizar pesquisas que explorem as diversas nuances do objeto velhice/envelhecimento na nossa sociedade, nos mais variados grupos sociais, e ainda, mostram a aplicabilidade da teoria em tais estudos na evidenciação dos processos que constroem tais representações e suas dinâmicas.

\section{REFERÊNCIAS}

1. Papaleo Netto M. Gerontologia: a velhice e o envelhecimento em visão globalizada. São Paulo (SP): Atheneu; 2005.

2. Beauvoir S. A velhice. Rio de Janeiro (RJ): Nova Fronteira; 1990.

3. Debert GG. As representações sociais (estereótipos) do papel do idoso na sociedade atual. In: Anais do I Seminário Internacional Envelhecimento Populacional: uma agenda para final do século, 1996; Brasília, Brasil. Brasília (DF): Ministério da Previdência e Assistência Social; 1996.

4. Jodelet D. Loucura e representações sociais. Petrópolis (RJ): Vozes; 2005.

5. Camarano AA, Kanso S. As instituições de longa permanência para idosos no Brasil. R Bras Est Pop. 2010 Jan-Jun; 27(1):233-5.

6. Martins JJ, Albuquerque GL, Nascimento ERP, Barra DCC, Souza WGA, Pacheco WNS. Necessidades de educação em saúde dos cuidadores de pessoas idosas no domicílio. Texto Contexto Enferm. 2007 Abr-Jun; 16(2):254-62.

7. Wagner W. Sócio-gênese e características das representações sociais. In: Moreira ASP, Oliveira DC, organizadoras. Estudos interdisciplinares de representação social. Goiânia (GO): ABP; 1998
8. Mendes MRSSB, Gusmão JL, Faro ACM, Leite RCBO. A situação social do idoso no Brasil: uma breve consideração. Acta Paul Enferm. 2005 OutDez; 18(4):422-6.

9. Brasil. Gabinete do Ministro de Estado da Saúde (BR). Portaria $\mathrm{N}^{\circ} 1.395$ de 9 de dezembro de 1999: aprova a Política Nacional de Saúde do Idoso e dá outras providências. Diário Oficial [da] República Federativa do Brasil, 13 Dez 1999. Seção I, n.237-E, p.20-4.

10. Maroun K, Vieira V. Corpo: uma mercadoria na pós-modernidade. Psicologia em Revista 2008 Dez; 14(2):171-86.

11. Oliveira CM. Literatura para crianças: espelho da sociedade brasileira [online]. [acesso 2007 Ago 15]. Disponível em: http://www.graudez.com.br/ litinf/trabalhos/velhice1.htm

12. Barros MML. Velhice ou terceira idade? Estudos antropológicos sobre identidade, memória e política. Rio de Janeiro (RJ): Editora Fundação Getulio Vargas; 1998.

13. Gatto IB. Aspectos psicológicos do envelhecimento. In: Papaleo Netto M, organizador. Gerontologia: a velhice e o envelhecimento em visão globalizada. São Paulo (SP): Atheneu; 2005.

14. Zimerman GI. Velhice: aspectos biopsicossocias. Porto Alegre (RS): Artmed; 2005.

15. Mercadante E. Aspectos antropológicos do envelhecimento. In: Papaleo Netto M, organizador. Gerontologia: a velhice e o envelhecimento em visão globalizada. São Paulo (SP): Atheneu; 2005.

16. Pavarini SCI, Mendiondo MSZ, Barham EJ, Varoto VAG, Filizola CLA. A arte de cuidar do idoso: gerontologia como profissão? Texto Contexto Enferm. 2005 Jul-Set; 14(3):398-402.

17. Rodrigues RAP, Kusumota L, Marques S, Fabrício SCC, Cruz IR, Lange C. Política nacional de atenção ao idoso e a contribuição da enfermagem. Texto Contexto Enferm. 2007 Jul-Set; 16(3):536-45. 